Rev. Est. de Políticas Públicas, 5(2): julio 2019 - noviembre 2019, 58-70

http://dx.doi.org/10.5354/0719-6296.2019.55354

ISSN edición web: 0719-6296

(C) Copyright 2019: Universidad de Chile, Santiago (Chile)

\title{
Políticas públicas, participación ciudadana y desarrollo local en el ordenamiento jurídico cubano: de la Constitución de 1976 a la de 2019
}

\author{
Óscar Echavarría Prade \\ Universidad de Oriente
}

\begin{abstract}
Resumen
El perfeccionamiento del sistema político, social y económico cubano pasa por buscar un modelo más eficiente, capaz de hacer frente a las demandas que se diversifican y amplían en el nuevo milenio, que reconozca el rol protagónico a las escalas locales. El proceso de perfeccionamiento y reacomodo del modelo económico cubano proyecta un marcado carácter descentralizador, en aras de dotar a los municipios y otros espacios locales de mayor autonomía en la gestión de las políticas públicas e incentivar la participación ciudadana. A tales fines, se han introducido cambios, incluso con anterioridad a la aprobación del nuevo texto constitucional. El presente artículo tiene como objetivo analizar desde una perspectiva teórica y normativa la participación ciudadana en las políticas públicas en el contexto cubano actual. El trabajo ha sido dividido en dos partes: en la primera se analiza la participación ciudadana en las políticas públicas en la Constitución de 1976 y en la segunda se examinan las referidas instituciones en los Lineamientos de la Política Económica y Social del Partido y la Revolución, en el Plan Nacional de Desarrollo Económico y Social hasta 2030 y finalmente se analiza la nueva Constitución cubana.
\end{abstract}

Palabras clave: participación ciudadana, políticas públicas, desarrollo local.

Political public, civic participation and local development in the Cuban juridical classification: of the Constitution of 1976 to that of 2019

\begin{abstract}
The improvement of the system political, social and economic Cuban goes to look for a more efficient model, able to make in front of the demands that are diversified and they enlarge in the new millennium that recognizes the protagonistic list to the local scales. The process of improvement and reacomodo of the pattern economic Cuban project a marked character descentralizador, for the sake of to endow to the municipalities and other local spaces of more autonomy in the administration of the public politicians and to motivate the civic participation. To such ends, changes have been introduced, even prior to the approval of the new constitutional text. The present article has as objective to analyze from a theoretical and normative perspective the civic participation in the public politicians and the local development in the current Cuban context. The work has been divided in two parts: in the first one the civic participation is analyzed in the public politicians and the local development in the Constitution of 1976 and in second o'clock the referred institutions are examined in the Limits of the Economic and Social Politics of the Party and the Revolution, in the National Plan of Economic and Social Development up to 2030 and finally the new Cuban Constitution is analyzed.
\end{abstract}

Keywords: political participation, public policy, local development

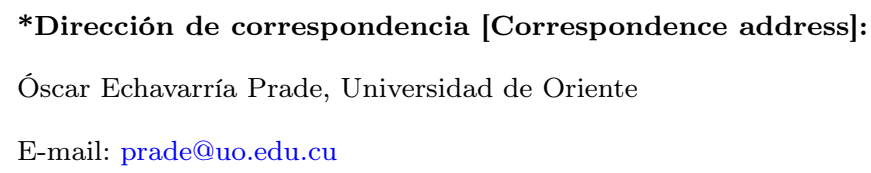




\section{Introducción}

En Cuba los estudios acerca del desarrollo local (en lo adelante DL) se han acrecentado en la última década. El tema ha sido abordado desde diferentes perspectivas (social, económica, ambiental); sin embargo, con independencia de la perspectiva desde donde se asume el estudio, una parte importante de los investigadores cubanos reconocen que se trata de un proceso de un elevado carácter participativo e interactivo entre los diferentes actores de la sociedad. Sorhegui y Segura afirman que el DL “(...) no es solo una estrategia político-institucional o no lo es exclusivamente, sino que es el resultado de la multiplicidad de acciones del conjunto de actores (económicos, sociales, políticos, culturales, tecnológicos y otros), que operan y toman decisiones en el territorio (...)" (León Segura y Sorhegui, 2007: 5-10). Ada Guzón, prestigiosa investigadora cubana en esta materia, enfatiza en que los procesos participativos, más allá de la consulta o la movilización, es uno de los aspectos que caracteriza una estrategia de DL (Guzón Camporredondo, 2015).

El análisis de la participación ciudadana en el DL se asume desde dos perspectivas. La primera, parte de reconocer el DL como una política pública (en lo adelante $\mathrm{PP}$ ) per se, que requiere de la intervención ciudadana en la construcción de la agenda política del propio DL; es decir, en la definición de las problemáticas que constituyen las prioridades centrales del DL a partir de la construcción del diagnóstico correspondiente. La segunda tiene su génesis en la definición y elaboración de las PP para dar respuesta al diagnóstico, en la implementación de las PP definidas y en el control de los resultados y efectos a corto, mediano y largo plazo a fin de realizar las correcciones necesarias al propio proceso de DL (Limia David, 2006). Desde esta perspectiva el estudio de la participación ciudadana en el DL atraviesa todo el constructo teórico que se ha elaborado alrededor de la participación de los ciudadanos en la gestión de las PP.

La manera en que se diseñan las políticas de desarrollo en las localidades cubanas da cuenta de una visión económica del proceso, obviando que el desarrollo local tiene en sus fundamentos procesos políticosjurídicos y sociales de los cuales dependen, en importante medida, sus resultados. Sin embargo, los estudios normativos en materia de políticas públicas, participación ciudadana no abundan en la academia cubana, a pesar de ser éste uno de los recursos por el que apuesta el nuevo modelo económico, político y social cubano.
El presente artículo constituye un acercamiento al tema, con el objetivo de identificar las principales insuficiencia y limitaciones normativas del ordenamiento jurídico cubano en materia de políticas públicas, participación ciudadana y desarrollo local. Para tales fines fueron utilizados como principales métodos: exegético, análisis-síntesis y revisión bibliográfica.

Políticas públicas, participación ciudadana, y desarrollo local en la constitución cubana de 1976: un camino de acierto y desaciertos.

La formulación de PP territoriales es una necesidad para el DL, como bien afirma Ada Guzón (2004: 12) "(...) capacidad de gobierno, en tanto capacidad de formulación y no sólo gestión de políticas". No obstante, en el ordenamiento jurídico cubano el tratamiento a las PP resulta limitado. En la carta magna cubana de 1976 no existe referencia explícita a esta institución, ni vinculada al DL, ni a la propia participación ciudadana. En este sentido la limitación primigenia está dada en el orden de la autonomía y las competencias, diríamos, autonomía política del ente municipal para elaborar PP y el reconocimiento de los órganos e instancias con potestades para tales fines $^{1}$. El artículo 102 de la Ley suprema de 1976 declara que el municipio es el ente local con capacidad para satisfacer las necesidades mínimas de su población, pero no define el sistema de competencias y funciones para el cumplimiento de ese fin. Este vacío normativo se hace más patente al no existir una Ley en estricto sensu que regule la vida de los municipios cubanos y establezca sus funciones y competencias. Empero, si asumiéramos como tal las funciones de su órgano ejecutivo, sentenciadas en el artículo 13 del Reglamento de las Administraciones Locales del Poder Popular ${ }^{2}$, no serviría más que para ratificar el referido punto de vista, es decir, la falta de autonomía política del ente municipal, considerando que la autonomía implica no solo la elección directa de las autoridades, sino también, la facultad de estas para instrumentar PP (Hernández Aguilar, 2014).

\footnotetext{
${ }^{1}$ En el marco de la ciencias políticas ha sido discutido con mucha fuerza en cuanto a la capacidad de los diferentes niveles de gobierno para formular políticas públicas, sin embargo las ventajas que reporta el dotar a todos los niveles del gobierno de esta capacidad son incuestionables: logran mayor eficiencia y hacen predecible el curso de acción del gobierno en los temas más importantes para la población, y se supera el empirismo estatal.

${ }^{2} \mathrm{El}$ artículo, entre otras cuestiones, dispone que el Consejo de la Administración tiene entre sus atribuciones coordinar, controlar y fiscalizar en su demarcación la ejecución de las políticas, programas y planes aprobados por los órganos superiores del partido, Estado y gobierno para el territorio.
} 
Estas inconsistencias en el más alto eslabón del ordenamiento jurídico cubano dejan un lastre sustancial en el resto del sistema, específicamente en torno al tema del DL y la participación ciudadana en procesos que forman parte de flujo de decisiones y acciones desplegadas por el gobierno en la gestión de las PP y que son su contenido visible, entiéndase: planificación, elaboración del presupuesto, manejo de las finanzas públicas. Esta situación se agrava si se tiene en cuenta, además, que en la mayor de las Antillas el DL carece de una base normativa sólida, uniforme y eficaz que contribuya con una práctica consecuente de este proceso.

En los municipios aparecen, en ocasiones superpuestas, variadas herramientas planificativas que rigen la actividad: Estrategias de Desarrollo Local, Planes de Desarrollo Integral, Planes de Ordenamiento Territorial y Urbano y de gran impacto han sido los Proyectos de Iniciativa Municipal de Desarrollo Local. Los principales instrumentos jurídicos que regulan este último proceso son: la Resolución Conjunta MES-MEP No. 001 de 2001, la Resolución 2387 del Ministerio de Economía y Planificación, Resolución No. 76/2000 del Banco Central de Cuba y la Metodología para el Diseño de Iniciativas Municipales de DL.

En la coexistencia de estas normativas y procedimientos se pierde el norte participativo de los ciudadanos, tanto en la elaboración de la propia estrategia de DL, como en la definición de las políticas públicas territoriales que deben acometerse para impulsar la estrategia. Primeramente por que se llega a una estrategia de DL a partir de un diagnóstico que no refleja en toda su magnitud los intereses de los diferentes actores comunitarios. En segundo lugar vuelve a resaltar como obstáculo la incapacidad de la instancia municipal para instrumentar PP construidas con la participación ciudadana. Es así que se pierde la posibilidad de utilizar la PP como herramienta para conocer las necesidades más sentidas de la localidad, y como instrumento de articulación entre los actores sociales y el gobierno, entre las demandas locales y los planes en los diferentes niveles; “(...) resulta indispensable la existencia de estrategias que obedezcan a políticas territoriales diseñadas, específicamente, para incidir en los mecanismos de desarrollo que forman parte del núcleo alrededor del cual se organizan y realizan los procesos de transformación y cambio de las economías" (Torres Páez y Gómez Ceballo, 2017: 65).

En este sentido existe un quebrantamiento del carácter integrador de la planificación desde una pers- pectiva territorial, por la excesiva centralización, y por el predominio de la planificación sectorial y ramal del desarrollo económico; "(...) la planificación de los municipios exige una visión de desarrollo local, que debe partir de la estrategia de desarrollo municipal, acordada de forma participativa por el Consejo de Administración Municipal (CAM), los delegados de los Consejos Populares y las entidades relevantes del municipio" (Torres Páez y Gómez Ceballo, 2017: 66), en fin por los principales actores económicos, sin obviar el sector privado. Por otra parte la visión temporal de la planificación debe ir más allá del período anual y optar por períodos relativamente más extensos que permita introducir criterios locales que pudieran nacer a mediano o corto plazo(Torres Páez y Gómez Ceballo, 2017)."La visión a mediano plazo se necesita para sustentar la toma de decisiones en términos de estrategia, de política económica y de sistema de dirección"(Méndez y Lloret, 2009:102).

Precisamente, entre las deficiencias que en su momento se señalaron de la experiencia, que a modo de experimento se desarrolló en las jóvenes provincias de Artemisa y Mayabeque ${ }^{3}$, está el hecho de que los municipios no cuentan con planes a largo plazo, así como la falta de integración entre los planes anuales, los emprendimientos locales, y las estrategias de DL y de estos con el presupuesto local (Mulet Concepción, 2015).

La vocación democrática y participativa del DL tiene en su génesis el manejo y control por parte de la ciudadanía de los fondos públicos, teniendo en cuenta que este es el motor que mueve la actividad pública en función del desarrollo (Hechavarria Prade, 2017). Consecuentemente, para impulsar un proyecto de DL el Estado cubano debe superar importantes escollos relacionados con la participación ciudadana y los fondos públicos: la centralización y verticalismo en la toma de decisiones con respecto a los fondos públicos, falta de autonomía económica y financiera de los gobiernos municipales, y la insuficiente participación ciudadana en la toma de decisiones.

A los fines de revertir este cuadro negativo resultaría beneficioso la publicidad de la actividad gubernamental, que se le informe a la población acerca del estado de la hacienda pública, que la ciudadanía se informe de todo lo concerniente a los ingresos y gastos públicos, en fin, introducir gradualmente prácticas del presupuesto participativo (Díaz Legón, 2015).

\footnotetext{
${ }^{3}$ Esta experiencia fue regulada por el Decreto 301 del 2012, que establece las nuevas funciones estatales y de gobierno que se ejercen y cumplen en las dos provincias y sus municipios.
} 
En lo tocante a la elaboración del presupuesto, ciertamente es una atribución de las Asambleas Municipales del Poder Popular (AMPP) elaborar la propuesta del presupuesto municipal ${ }^{4}$. Esta propuesta se presenta a la Dirección Provincial de Finanzas y a la Asamblea Provincial correspondiente y posterior a su evaluación a este nivel se presenta ante el Ministerio de Finanzas y Precios quien a su vez lo analiza y eleva a la Asamblea Nacional del Poder Popular (ANPP) para su definitiva aprobación mediante Ley (Pérez Hernández y Prieto Valdés, 2004). Una vez aprobado el presupuesto se le notifica a la Dirección Provincial de Finanzas y este lo distribuye por esferas.

En cuanto al control del presupuesto, este comienza desde el mismo inicio de la ejecución del presupuesto. El ejercicio del control se efectúa por los administradores de la unidad gestora y por los niveles superiores mediante comprobaciones de gastos que se realizan al menos una vez al año (Santos Cid y Peralta de Valle, 2003).

Este es el punto crítico del análisis, por lo expuesto en el procedimiento se advierte que la actividad presupuestaria local (dígase diseño, ejecución y control) es ajena a los ciudadanos, es una actividad personalísima de los órganos del Estado, y aun cuando es atribución de la AMPP elaborar el proyecto presupuestario, la aprobación final se convierte en un acto formal en la medida en que el documento es modificado y aprobado en otras instancias superiores (Pérez Hernández y Prieto Valdés, 2004). "La aprobación de los presupuestos municipales deviene un acto formal y no un instrumento de iniciativa estatal local. Con ello, se limita el cumplimiento del rol del delegado y se minimiza su figura, a su vez, se resta sustancia al proceso del que forma parte y mantiene la transferencia de la soberanía popular hacia la sede del gobierno" (Guanche, 2012).

Para la realización y desarrollo de sus actividades, los presupuestos locales a tenor del Decreto Ley 192, cuentan con las siguientes fuentes de ingresos: ingresos cedidos, provienen de los recursos que aportan las entidades de subordinación local y otros que por su procedencia están asociados a una erogación que tuvo o tiene que realizar la localidad; ingresos participativos, corresponden al Presupuesto Central y se otorga un tanto por ciento de participación de lo recaudado en la localidad, de los cuales la participación se autoriza del Impuesto Sobre Utilidades de

\footnotetext{
${ }^{4} \mathrm{Al}$ respecto puede consultarse. Reglamento de las Asambleas Municipales del Poder Popular, aprobado por acuerdo del Consejo de Estado, de 13 de septiembre de 1995.
}

las empresas de subordinación nacional y de determinados productos del Impuesto sobre las Ventas y de Circulación (Santos Cid y Peralta de Valle, 2003).

Esta perspectiva para manejar los ingresos fiscales municipales resulta poco factible para asumir un proyecto de DL por el nivel de centralismo y verticalismo que encierra. De la letra de la norma puede advertirse que es muy estrecho el margen de decisión que se le otorga a los municipios en cuanto a la exacción y disposición de ingresos, en tanto gran parte de los ingresos es cedido y manejado desde los niveles centrales e intermedios de la estructura estatal (Santos Cid y Peralta de Valle, 2003). Con esta medida se pretende equilibrar financieramente todos los municipios mediante un proceso de redistribución realizado por la instancia provincial. Con todo, es cuestionable hasta qué punto resulta racional y estimulante para incentivar el trabajo de los municipios que los ingresos generados por ellos sean administrados por el nivel provincial más allá de cualquier pretensión de búsqueda de un equilibrio monetario entre los municipios (Santos Cid y Peralta de Valle, 2003).

En este sentido se precisa, ante todo, fortalecer la capacidad fiscal de los municipios. La perspectiva es facultar a las localidades para incidir en la variación de la política fiscal que le afecta. Díaz Díaz Legón (2015) hace referencia específicamente a que los municipios puedan variar cuestiones como la base imponible o el tipo impositivo. Como segundo aspecto se debe potenciar la obtención de recursos financiaros o al menos crear las vías para ello. Los municipios deben contar con un presupuesto creado a partir de los propios esfuerzos y potencialidades del territorio que a la vez estimule el trabajo en la medida que esos resultados se traduzcan en prosperidad y nivel de vida para el territorio (Díaz Legón, 2015).

A estos fines, el sistema tributario es utilizado como vía para solventar la necesidad acuciante de financiamiento que presentan las localidades para su desarrollo. En el título III de la Ley 113 de 2012, Art. 314 se regula una contribución para el desarrollo sostenible de los municipios, que grava los ingresos por la comercialización de bienes o prestación de servicios que obtengan las empresas, sociedades mercantiles y cooperativas por sí mismas y por sus establecimientos en cada territorio ${ }^{5}$. El tipo impositivo de esta contribución quedará determinado por la Ley anual del presupuesto. La base imponible estará constituida por la totalidad de los ingresos pro-

\footnotetext{
${ }^{5}$ Véase artículo 314 de la Ley 113 del Sistema Tributario. Cuba (2012)
} 
venientes de la venta de bienes y la prestación de servicios de los sujetos pasivos (las empresas, las sociedades mercantiles de capital totalmente cubano y las cooperativas, por sus establecimientos).

Estas transformaciones implican un giro a una política centrista que ha constituido por más de cuatro décadas el eje de la economía cubana, pese a ello resulta cuestionable hasta qué punto esta transferencia de poder constituye una verdadera descentralización. Como bien aclara la ciencia política "(...) lo fundamental de la descentralización sería su dimensión política, es decir, el constituir una redistribución espacial del poder democrático en provecho de las comunidades locales" (Boisier, 2007: 38). Bajo tales presupuestos crear o perfeccionar los canales participativos que permitan a los ciudadanos tomar parte en el destino y control del presupuesto asignado a los municipios para el DL resulta una tarea pendiente que requiere de urgencia en el actual contexto cubano (Hechavarria Prade, 2017).

El modo de organizar y relacionar los actores económicos en la sociedad es otro de los procesos centrales dentro del plano funcional que caracteriza un modelo económico(Fernández, 2012). En un proyecto de DL se hace necesario perfeccionar las instituciones jurídicas relacionadas con el comportamiento de los actores, de manera que se logre una adecuada articulación entre todos los protagonistas del proceso y entre estos y el gobierno.

Los estudios acerca de los actores de la participación ciudadana distinguen entre actores estatales y privados, entre actores individuales y colectivos; estos últimos han adquirido gran relevancia en el ejercicio de la participación ciudadana y el DL, especialmente por su relación directa con el enfoque de redes (Policy network y la gobernanza). Es en este marco que para el DL y la participación ciudadana adquiere protagonismo la capacidad asociativa, condicionada por las normas jurídicas y reglas de actuación propias de los distintos ámbitos.

El derecho de asociación en Cuba es reconocido en el artículo 53 de la Constitución de 1976 como medio a través del cual los ciudadanos pueden realizar múltiples actividades científicas, culturales, recreativas, solidarias y de beneficio social. Según Guanche (2012) en la Ley suprema de 1976 existe un desarrollo limitado del derecho de asociación en tanto los derechos, principios y valores que el texto consagra se centran en el ciudadano, aún y cuando en el discurso institucional se apuesta por un rol protagónico de los grupos sociales. "En ese horizonte, puede ser útil establecer reglas de acceso mínimo al aparato estatal a favor de grupos sociales desfavorecidos, y regular que las distintas formas de organización de la sociedad cuenten con canales para dirigir directamente demandas al Estado y poder verlas, también, representadas ante el respectivo órgano deliberativo estatal" (Guanche, 2012:75).

El derecho de asociación quedó desarrollado por la Ley No 54, vigente desde el 27 de diciembre de 1985. Los propios fundamentos de hechos que sustentan la normativa refuerzan el criterio de una nueva legislación ajustada a las necesidades del momento y que responda al creciente interés demostrado por la población respecto a la constitución y desarrollo de las asociaciones de bien social.

A tales efectos la citada noma en su artículo 2 instituye las asociaciones que podrán constituirse conforme a fines preestablecidos, y siempre en el marco de un interés social: a) Científicas o técnicas, b) culturales y artísticas, c) deportivas, ch) de amistad y solidaridad, d) otras que conforme a la Constitución y a esta Ley se propongan fines de interés social.

La concepción de los tipos y fines asociativos recogidos en la referida norma, en la actualidad, se ven desbordadas por la nueva realidad económica política y social que vive la Cuba de las dos últimas décadas. Pérez Chaguaceda (2008) señala cómo en la década del 90 se asiste a un crecimiento del asociacionismo en Cuba influenciado por el derrumbe del campo socialista y cierto nivel de desapego a un modelo de gobierno estatista y centrista. Por otra parte, apunta el autor, aparecen tendencias asociativas como resultado de movimientos de solidaridad con Cuba. Desde la mirada económica emergen nuevas formas asociativas con nuevos fines, dígase empresas mixtas y cooperativas. Por último, refiere, no pueden pasar desapercibidas determinadas asociaciones -vinculadas a tendencias sexuales, culturales, espirituales y de fundamentos profesional- que aunque con carácter informal empiezan a ser visibles en el escenario cubano actual.

En este complejo y diversificado escenario actoral, la Ley 54 resulta muy restricta, no únicamente en cuanto a los tipos y fines asociativos, también en la concepción de las relaciones para el cumplimiento de sus objetivos y el desarrollo de sus actividades. En relación a este último aspecto, el artículo 11 de la tan citada Ley, dispone que las asociaciones únicamente mantengan relaciones de coordinación y colaboración con órganos, organismos o dependencia estatal, y aquellas que tengan relación con los obje- 
tivos y las actividades que desarrollará la asociación que se pretende constituir.

La Ley 54 no reconoce las relaciones fuera del marco estatal como las que pudieran establecerse entre las propias asociaciones con otros fines. De esta manera, la norma frena la conformación y desarrollo interactivo de los actores en la sociedad. Este es uno de los puntos más insuficiente de la norma, en tanto el derecho a la libertad de asociación queda limitado en sus fines, tipos y en la capacidad de interacción. Resultado de tan restricto maro normativo, se soslayan procesos que tienen una génesis interactiva entre actores colectivos como son el DL y la participación ciudadana.

De los actores privados mucho se ha dicho en cuanto al papel que deben jugar en la economía, pero poco se ha escrito desde la perspectiva normativa, acerca del papel que juegan en la planificación y el desarrollo, así como sus relaciones con el resto de los actores sociales y específicamente con el Estado en torno al rol que le corresponde frente a los problemas públicos. En efecto, el texto constitucional de 1976 no desarrolla en toda su dimensión ésta forma de propiedad. Sigue prevaleciendo una concepción estatalista de la planificación que cierra las puertas a otras formas de propiedad, dígase, el sector privado, y las abre a formas de abastecimiento y de distribución ilegales que debilitan la efectividad del plan y la política tributaria (Pérez y Arguelles, 2011).

En este orden de cosas perseveran los problemas del alto nivel de centralización política, que al decir del sociólogo Valdés Paz: "Los avances en la descentralización de facultades, de recursos e información a favor de sectores no estatales o de instancias locales del Estado, han sido más que insuficientes. En gran medida el orden institucional muestra una alta centralización en todos los sistemas lo cual es en parte un efecto de las condiciones ambientales en que se desenvuelven y en parte un efecto de su diseño institucional y de la alta centralización del poder político (...)" (Valdés, 2015:6).

\section{Antesala de una nueva constitu- ción: políticas públicas, participa- ción ciudadana y desarrollo local}

La participación ciudadana en las PP y el DL adquiere mayor dimensionamiento en el ordenamiento jurídico cubano a partir de la implementación de los Lineamientos de la Política Económica y Social del
Partido y la Revolución (lineamientos) y su posterior configuración en la conceptualización del modelo económico y el Plan Nacional de Desarrollo Económico y Social hasta 2030: Propuesta de Visión de la Nación, Ejes y Sectores Económicos Estratégicos (PDE). El primer mérito de ambas normativas ${ }^{6}$ es que modelan el desarrollo del país a partir de una interacción entre las dimensiones políticas económicas y sociales, que se inscribe dentro de un modelo de gobernanza local ${ }^{7}$. Se trata de un proyecto sustentado en un prototipo de gobierno más horizontal, con una amplia interacción entre un núcleo diverso de actores que pretenden el desarrollo mediante políticas que surgen desde los gobiernos locales y regionales para impulsar la competitividad territorial y la integración con otros territorios.

Los lineamientos conciben el DL como el eje articulador en la construcción de una sociedad próspera y sostenible, particular que se visualiza en la normativa cuando establece entre sus objetivos: "Impulsar el desarrollo de los territorios a partir de la estrategia del país, de modo que se fortalezcan los municipios como instancia fundamental, con la autonomía necesaria, sustentables, con una sólida base económico-productiva, y se reduzcan las principales desproporciones entre estos, aprovechando sus potencialidades" (Asamblea Nacional del Poder Popular, 2011). En esta dirección se enrumban un grupo de lineamientos con base en principios como la descentralización, la autonomía y la participación de todos los actores locales ${ }^{8}$.

El PDE, constituye el punto más alto del ordenamiento jurídico patrio en cuanto a la proyección y concepción de la participación ciudadana en las PP y el DL. Si bien el proyecto no alude de forma directa a la categoría gobernanza, los principios que sustenta esta forma de gobierno subyacen cuando

\footnotetext{
${ }^{6}$ En la literatura consultada encontramos puntos de vistas diferentes en cuanto al alcance normativo de ambos documentos, por ejemplo Reinier Limonta considera que al ser estos (lineamientos) aprobados por la Asamblea Nacional del Poder Popular en 2011 y en virtud del mandato del art.70 de la Constitución, se convierten en norma vinculante para la política estatal cubana. Véase Limonta Montero (2017). Sin embargo para Hernández Duartes los lineamientos no constituyen normativas, véase Hernández Duartes D., (2014).

${ }^{7}$ El criterio de que los Lineamientos de la Política Económica y Social del Partido y la Revolución, la Conceptualización del Modelo Económico y Social Cubano de Desarrollo Socialista, y el Plan Nacional de Desarrollo Económico y Social hasta2030: Propuesta de Visión de la Nación, Ejes y Sectores Económicos Estratégicos, en su conjunto conforman un modelo de gobernanza es sostenido por otros autores como Limonta Montero (2017), y Rodríguez Cruz (2018).

${ }^{8}$ Véanse lineamientos 21, 37, 61, 103, 120, 121, 139, 159, 163, 178, 180, 185, 205-207, 233, 239, 263, 264.
} 
se analizan los ejes estratégicos y objetivos que lo conforman.

El eje estratégico gobierno eficaz y socialista e integración social comienza por reconocer la necesidad de perfeccionamiento del nivel territorial en el sentido de lograr mayor nivel de articulación entre el nivel central y el territorial con la finalidad de potenciar la eficiencia y eficacia de las PP y su capacidad para promover el desarrollo (Plan Nacional de Desarrollo Económico y Social hasta 2030, 2016). Dos cuestiones relevantes se interpretan al respecto, por un lado se reconoce la capacidad de las localidades, (municipio y provincia) para elaborar PP territoriales, cuestión que luego es refrendada de forma directa dentro de este eje estratégico cuando se plantea: "Los órganos del Estado y sus actuaciones en los respectivos espacios desempeñan un papel crucial en la formulación y la implementación de las PP" (Plan Nacional de Desarrollo Económico y Social hasta 2030, 2016). Por otro lado, se patentizan los efectos positivos que tiene sobre el DL y las PP una adecuada articulación entre los diferentes niveles territoriales del Estado, a partir de un proceso descentralizador portador de una perspectiva equilibrada entre el nivel central y los territorios.

La visión participativa es latente en todo el texto del proyecto, y en tal sentido dentro de los objetivos del citado eje estratégico se propone como meta un ciudadano con mayor grado de cultura política y jurídica, más preparado para involucrarse en los problemas públicos. Consecuentemente con estos basamentos se les otorgan importantes facultades a los actores sociales y económicos, potenciándose los niveles de interacción de éstos con el Estado y un mayor protagonismo en el desarrollo local, y el internacional.

Este particular se patentiza al establecerse como objetivo especifico: "(...) alcanzar el desarrollo territorial mediante el fortalecimiento de las atribuciones y las capacidades de planificación y gestión de los territorios, la participación de los actores sociales y la coordinación con otras instancias del Estado, a fin de potenciar los recursos locales y aprovechar las oportunidades de los mercados internacionales y de la sustitución de importaciones en el mercado nacional" (Plan Nacional de Desarrollo Económico y Social hasta 2030, 2016). A tales fines, dentro del mismo eje estratégico, se propone como finalidad la consolidación de un marco regulatorio que ordene el funcionamiento de los actores sociales y económicos.

El papel de los actores y la participación ciudada- na son puntales fundamentales en otros ejes estratégicos como el de Transformación productiva e inserción internacional. Es así que se traza como propósito una mayor unificación de los actores económicos a fin de "(..) lograr una mayor integración entre los actores económicos del país que dé respuesta oportuna a las demandas del mercado interno, tanto del sector productivo como de la población" (Plan Nacional de Desarrollo Económico y Social hasta 2030, 2016). Igualmente el eje estratégico Desarrollo humano, equidad y justicia, fundamenta la idea del desarrollo sobre la base de las potencialidades de los diferentes actores sociales y la participación a partir de proyectos individuales y familiares. El compromiso del proyecto con la participación ciudadana y el desarrollo local se refuerza desde el ámbito planificativo al disponerse "(...) la planificación centralizada y participativa como componente principal del sistema de dirección económica y social" (Plan Nacional de Desarrollo Económico y Social hasta 2030, 2016).

\section{Un nueva Constitución en Cuba: aportes en materia de políticas pú- blicas, participación ciudadana y desarrollo local}

El debate en torno a la necesidad de reformar el texto magno cubano de 1976 circundó los principales círculos académicos y científicos de Cuba como visión primigenia de los cambios que luego necesariamente comenzaron a introducirse con los Lineamientos de la Política Social y Económica del Partido y la Revolución, la Conceptualización del Modelo Económico y Social de Desarrollo Socialista, de conjunto con el Plan Nacional de Desarrollo Económico y Social hasta 2030. Y es que la implementación de estos instrumentos normativos constituye un paso necesario en el proceso de institucionalización a que convocó el entonces Presidente y actual Primer Secretario del Partido Comunista de Cuba Raúl Castro Ruz. Las instituciones, las normas y entre ellas la carta suprema ya no responden eficazmente a la realidad política, económica y social que se vive en la nación antillana y consecuentemente no responderían a un proyecto futuro. Estos fundamentos son expuestos a posteriori por el propio constituyente en la introducción al proyecto constitucional cuando expresa que la nueva carta magna responde a la necesidad de hacer corresponder la constitución con nuestra realidad y el futuro previsible.

En medio de estas tensiones el anuncio de una reforma al texto constitucional cubano acontece el 13 
de abril de 2013 en voz del compañero Raúl Castro Ruz, entonces Presidente de los Consejos de Estado y de Ministros y Primer Secretario del Partido Comunista de Cuba (PCC). En ocasión de ello, el Buró Político creó un grupo de trabajo, que presidido por el propio compañero General de Ejercito Raúl Castro Ruz inició un largo proceso de estudio y análisis en aras de determinar los posibles cambios constitucionales. Finalmente, el parlamento en ejercicio pleno de sus facultades constituyentes aprueba una comisión que asumió la redacción del proyecto constitucional, en pos de su posterior consulta popular. Luego de un amplio y profundo proceso de consulta, en el periodo de sesión ordinaria de diciembre de 2018 el órgano legislativo cubano aprueba el nuevo texto constitucional que es aprobado por el pueblo cubano mediante referendo celebrado el 24 febrero de 2019.

En materia de participación el nuevo texto constitucional es superior al de 1976. La joven carta magna, tal como lo hacía la anterior, reconoce la participación directa y la representativa, así queda establecido a modo de principio en el artículo 3 de la Ley suprema ${ }^{9}$.

Trascendente resulta el reconocimiento de la participación como un derecho fundamental, específicamente como un derecho político ${ }^{10}$, cuestión que no aconteció en la carta magna de 1976. Desde esta perspectiva se da un importante paso en el camino de fortalecer el modelo participativo cubano a partir de su principal base legal. El constituyente otorga a la participación la más alta protección que puede adquirir un derecho en el ordenamiento jurídico, más allá de su constitucionalización, al otorgarle rango de derecho fundamental. Este posicionamiento necesariamente comprometerá un amplio despliegue de acciones legales y materiales por parte del Estado para garantizar el ejercicio efectivo de este derecho.

En virtud de ello el artículo 80 ubicado en Título V. Derecho, Deberes y Garantías, específicamente en el Capítulo II, regula el derecho de todo ciudadano a participar en la conformación, ejercicio y control

${ }^{9} \mathrm{El}$ artículo establece concretamente: "En la República de Cuba la soberanía reside intransferiblemente en el pueblo, del cual dimana todo el poder del Estado. El pueblo la ejerce directamente o por medio de las Asambleas del Poder Popular y demás órganos del Estado que de ellas se derivan, en la forma y según las normas fijadas por la Constitución y las leyes".

${ }^{10} \mathrm{En}$ el proyecto de constitución este derecho fue incluido dentro de los derechos políticos, luego en el texto final desaparecen los criterios clasificativos, sin embargo, por su contenido se puede afirmar que estamos ante un derecho político (participación política). del poder del Estado; luego como contenido y en aras de garantizar este derecho otorga a la ciudadanía un grupo de facultades: a) estar inscripto en el registro electoral; b) proponer y nominar candidatos; c) elegir y ser elegido; d) participar en elecciones, plebiscitos, referendos, consultas populares y otras formas de participación democrática; e) pronunciarse sobre la rendición de cuenta que le presentan los elegidos; f) revocar el mandato de los elegidos; g) ejercer la iniciativa legislativa y de reforma de la Constitución; h) desempeñar funciones y cargos públicos, y i) estar informado de la gestión de los órganos y autoridades del Estado.

El artículo de referencia tiene un importante precedente en el 131 de la constitución de 1976, además de integrar parte del contenido del 88 (iniciativa legislativa) y el 75 (consulta popular). En esencia, el artículo 80 del texto constitucional entraña una incuestionable progresión porque determina la participación como un derecho fundamental, además amplía y a la vez concreta su contenido al invocar el fenómeno participativo en sus tres dimensiones fundamentales, dígase conformación, ejercicio y control del poder y no la limita "a intervenir en la dirección del Estado" "11, tal como establecía la carta magna de 1976 .

Finalmente, desde una perspectiva bastante concordante con las más modernas tendencias de la democracia participativa, el constituyente define las acciones que puede acometer el ciudadano para el pleno ejercicio de este derecho indicando de manera indirecta los instrumentos participativos a tales efectos y dejando abierto el camino para las normas de desarrollo.

En relación a las acciones que puede efectuar el ciudadano, a fin de hacer efectivo el derecho reconocido (conformación, ejercicio y control del poder del Estado) el artículo que se analiza recoge dos perspectivas que resultan novedosas con respecto a la norma suprema que le precede: a) pronunciarse sobre la rendición de cuenta que le prestan los elegidos; b) estar informado de la gestión de los órganos y autoridades del Estado. En el primero de los casos, la norma revela de manera indirecta un actuar de los elegidos en el sentido de rendir cuenta de sus actos a los electores; no obstante la facultad otorgada al mandante para pronunciarse respecto a la rendición de cuenta resalta como designio directo de la nor-

\footnotetext{
${ }^{11}$ Este es el término utilizado en el artículo 131 de la Constitución cubana de 1976, en cuestión resulta un término bastante impreciso para definir el ámbito objetivo de la participación.
} 
ma en cuestión. Este esquema denota el interés del constituyente porque la rendición de cuenta resulte un espacio para el debate, la tematización, el diálogo y de una forma menos explícita, un instrumento para la evaluación de los actos de los elegidos.

El segundo de los casos, se inscribe en el proyecto del derecho a la información en el marco específico de la gestión pública, que tiene entre sus fines poner los medios informativos y la nueva tecnología en función de la participación ciudadana y la democracia. Por una parte, emerge el derecho de los ciudadanos a conocer de los actos del gobierno, en la otra cara de la moneda la obligación de los gobernantes de transparentar la actividad pública, es decir, hacer visible su gestión ante los ciudadanos, más allá de que quieran o no informarse. En este sentido se genera una interrogante interesante: ¿El derecho de los ciudadanos a estar informados de la actividad del gobierno genera por si sólo la obligación del Estado de hacer públicos sus actos? Con independencia del papel que puede jugar la norma implementadora, consideramos que la forma en que está enfocado el artículo "estar informado de la gestión de los órganos y autoridades del Estado" deja un sabor a inercia en los ciudadanos.

No debería defenderse únicamente el derecho a estar informado. Al mismo tiempo la norma debe pronunciarse por el derecho ciudadano de accionar frente al Estado para obtener la información. Por otra parte, resulta llamativo que el derecho a estar informado esté restringido únicamente a los actos del Estado y sus órganos. No resultaría para nada especulativo que el derecho a estar informado no recayere únicamente sobre la gestión del Estado y sus órganos, podría tener en su objeto toda la actividad pública aunque no sea generada directamente desde el Estado.

En el ámbito local el esquema participativo presenta importantes novedades que lo ponen a tono con las tendencias más modernas. Primeramente se diseña una estructura de los órganos estatales favorable a la participación en el ámbito local, toda vez que desaparecen las estructuras asamblearias provinciales y en su lugar se instituye un órgano de gobierno, según lo define el artículo 167 del texto constitucional. Este nuevo órgano cumplirá funciones estrictamente administrativas según sentencia el artículo 174. Al quedar eliminado el referido ente representativo, el municipio gana en autonomía política y administrativa, en tanto el citado ente provincial absorbía facultades decisionales al órgano asambleario municipal. En este sentido no se puede per- der de vista que la autonomía favorece los procesos democráticos y participativos al convertir a los municipios en el espacio político de los ciudadanos.

La perspectiva de otorgar autonomía a los municipios se establece de manera directa en el artículo 168 al definirse el municipio como "(...) la sociedad local, organizada por la ley, que constituye la unidad política-administrativa primaria y fundamental de la organización nacional; goza de autonomía y personalidad jurídica propias a todos los efectos legales (...)". Siguiendo esta línea el 169 declara el contenido de la autonomía, tanto política como administrativa, al reconocerle al municipio capacidad para la elección o designación de sus autoridades, la facultad para decidir sobre la utilización de sus recursos y el ejercicio de las competencias que le corresponden, dictar acuerdos y disposiciones normativas necesarias para el ejercicio de sus facultades. Sin embargo, es llamativo que como parte de la autonomía política, no se le atribuye al ente local capacidad para generar PP territoriales.

Como segunda nota relevante, está la distinción que de manera acertada hace el constituyente entre la participación política y la participación ciudadana. Reconoce la primera como derecho fundamental con pertinente aplicación en los niveles superiores de la estructura del Estado, como bien se explicó supra, no siendo así en el caso de la participación ciudadana, que no es reconocida como un derecho fundamental, la circunscribe al ámbito municipal, y le otorga como ámbito objetivo los asuntos públicos locales.

En este propósito de alcanzar mayores niveles de participación ciudadana en el nivel local, en una lógica poco ortodoxa, el constituyente opta por no constitucionalizar de manera directa los mecanismos participativos. En cambio en el artículo 200 del texto relaciona un conjunto de acciones que debe desplegar la Asamblea Municipal de Poder Popular a los efectos de garantizar los derechos de petición y de participación ciudadana: convoca a consulta popular, vela por el adecuado nivel de información de la población, analiza a pedido de los ciudadanos acuerdos o disposiciones que puedan afectar los intereses de estos, garantiza a los ciudadanos proponer el análisis de determinados temas y finalmente deja abierta la posibilidad de cualquier otra acción en aras de asegurar el ejercicio de los derechos sentenciados supra. Queda entonces para el legislador ordinario la facultad de instituir los mecanismos participativos que permitirán a los ciudadanos el ejercicio de estas garantías. 
El recurso utilizado por el constituyente puede considerarse favorable en tanto facilita las variaciones de los instrumentos participativos al quedar éstos supeditados a una norma ordinaria que goza de mayor flexibilidad ante las posibles modificaciones que se demanden, como resultado de los cambios sociales, políticos; empero a cambio se paga el alto precio de dejar los mecanismos participativos fuera de la mano protectora de la constitución ${ }^{12}$.

Queda a cargo del órgano legislativo decidir los mecanismos de participación ciudadana a implementar en la municipalidad cubana, aún es pronto para dar un veredicto, sin embargo atenidos a las garantías dispuestas en el artículo 200 se pueden vaticinar algunas variantes de instrumentos para la participación ciudadana, que podrían verse limitados a tenor del insuficiente tratamiento de las PP en la norma suprema.

En efecto, de las instituciones analizadas, las PP es el punto más limitado dentro del nuevo texto magno. La nueva carta magna tiene el gran mérito de introducir por vez primera la categoría política pública en el ordenamiento jurídico cubano, sin embargo, no logra un tratamiento normativo coherente, sistémico y ordenado de la institución, que la convierta en una herramienta efectiva para la actividad de gobierno, no solo como prerrogativa de orden local, sino también en los restantes niveles de la estructura estatal.

En primer orden, existe alusión a la institución en artículos muy puntuales y aislados. Al respecto el artículo 184 ordinal f) dispone como facultad del Consejo Provincial: "aprobar las propuestas de políticas que contribuyen al desarrollo integral de la provincia, antes de su presentación al Consejo de Ministros". Se trata de un artículo con muchas limitaciones, porque no define el tipo de política de que se trata y por otra parte al no existir un tratamiento sistémico de la institución dentro de la Ley suprema no queda explícito quién, cómo y en qué nivel de la estructura estatal se elaboran las referidas políticas. Igualmente queda como interrogante para qué se presentan las PP al Consejo de Ministros, en tanto, no tiene este órgano del Estado constitucionalmente reconocida ninguna prerrogativa vinculadas a las

\footnotetext{
${ }^{12}$ Es en los textos constitucionales donde suelen disponerse los mecanismos que viabilizan la participación de los ciudadanos en las políticas pública y luego estos son desarrollados en una Ley ordinaria. En este sentido destaca la carta magna ecuatoriana, que en el artículo 100 establece como mecanismos participativos: audiencias públicas, veedurías, asambleas, cabildos populares, consejos consultivos, observatorios y las demás instancias que promueva la ciudadanía.
}

$\mathrm{PP}^{13}$

Otros aspectos considerados por la Ley respecto a las PP, con las mismas limitantes, los encontramos en los artículos 44 y $71^{14}$. En el primer artículo se invoca la categoría PP como herramienta del Estado para garantizar la igualdad de los ciudadanos, en el segundo, como instrumento para hacer efectivo el derecho a una vivienda digna.

Por otra parte, al no reconocerse la autonomía municipal para generar PP, el derecho de los ciudadanos a participar en las PP, queda limitado en la misma medida que le ha sido constreñida la capacidad al ente local. Incluso, se plantea que la autonomía local es una garantía para el ejercicio de determinados derechos fundamentales en el ámbito local (Bastida et. al., 2004: 101). En este caso, la autonomía municipal opera como una especie de límite al contenido del derecho, al menos en lo que sería su contenido esencial -participar en la formulación, adopción, implementación y control de las PP_ ${ }^{15}$. De conformidad con el 191 constitucional, el órgano asambleario local está facultado únicamente para coadyuvar a la ejecución de las políticas del Estado en su demarcación. Siendo así, sería poco probable que el derecho de participación ciudadana en las políticas públicas, pueda ser ejercido más allá de este marco, es decir, pueda ser desplegado en todo su contenido (formulación, adopción, implementación y control de las PP).

El contenido del derecho de participación ciudadana en las PP, entendiendo como tal "(...) el poder o conjunto de poderes jurídicos, concebidos como facultades, mediante los que se hace valer frente a terceros el permiso o la prohibición iusfundamental garantizadas en cada derecho fundamental", es una cuestión que no queda resuelta por la constitución cubana de 2019. El citado artículo 200, resulta escabroso en este aspecto, en tanto estipula como garantías lo que bien pudo ser parte del contenido del derecho. El artículo de referencia relaciona un conjunto de acciones que debe desplegar la Asamblea Municipal de Poder Popular a los efectos de garantizar los derechos de petición y de participación ciudadana: convoca a consulta popular, vela por el adecuado

\footnotetext{
${ }^{13}$ Véase artículo 137 de la Constitución de la república de Cuba de 24 de febrero de 2019.

${ }^{14}$ En estos artículos el término utilizado es "política pública", no así en los artículos 184 y 195 c que se utiliza el término "política". Esto a la postre creará contradicciones y problemas de interpretación por tratarse de un término tan polisémico.

${ }^{15}$ Entiéndase como contenido esencial el conjunto de potestades que el derecho otorga a su titular y hace que el derecho sea ese y no otro, sin lo cual el derecho sería irreconocible.
} 
nivel de información de la población, analiza a pedido de los ciudadanos acuerdos o disposiciones que puedan afectar los intereses de estos, garantiza a los ciudadanos proponer el análisis de determinados temas de su competencia y finalmente deja abierta la posibilidad de cualquier otra acción en aras de asegurar el ejercicio de los derechos sentenciados supra. Luego, será en sede legislativa donde se establecerá la forma y el ejercicio de estas garantías.

Como puede interpretarse de la letra del referido artículo, el constituyente aspira a garantizar el derecho de participación ciudadana, invocando la garantía de otros derechos. Parece una obviedad que el "derecho de participación ciudadana" y los definidos como garantías en este artículo, quedarán asegurados para su ejercicio efectivo, en parte importante, en la medida que el legislador instituya los mecanismos participativos, instancias y procedimientos que garanticen el contenido del derecho, mismos que no refrendó dentro del texto magno.

Otro problema es, que al no reconocerse las principales potestades y facultades que son parte del contenido del derecho de participación ciudadana en los asuntos públicos, (participar en los procesos planificativos, elaboración y control del presupuesto, gestión de las finanzas públicas, organizarse en colectivos sociales y organizaciones representativas de los ciudadanos y las ciudadanas, presentar proyectos de desarrollo, acceder a la información pública etc.) se dificulta, en sustancial medida, garantizar desde su base constitucional el ámbito objetivo de libertad protegido por el derecho y su posterior salvaguarda en sede legislativa, mediante los mecanismos, instancias y procedimientos participativos ${ }^{16}$.

\footnotetext{
${ }^{16} \mathrm{El}$ derecho de participación ciudadana en las políticas públicas o la gestión de los asuntos públicos, ha sido poco estudiado desde el ámbito teórico normativo, específicamente en cuanto a la definición de los elementos configuradores del derecho (naturaleza, sujetos, objeto, contenidos, límites, garantías); esta temática es un campo de la ciencia en el cual debe seguirse profundizando. No obstante, estudios de Derecho Comparado de modernas Constituciones (Ecuador, Bolivia, Venezuela) arrojan como tendencia, el reconocimiento de la participación en los procesos planificativos, elaboración y control del presupuesto, gestión de las finanzas públicas como parte del ámbito objetivo del derecho. En esta misma línea se pronuncia la Carta Iberoamericana de Participación Ciudadana en la Gestión Pública en su artículo 35, aprobada por los Ministros de Administración Pública y de la Reforma del Estado y los Jefes de delegación de los países Iberoamericanos reunidos los días 25 y 26 de junio de 2009. En cuanto al sujeto del derecho, existe cierto consenso en reconocer como tal a la persona, sin que medie la condición de ciudadano, igualmente se reconocen las diferentes formas de organización de la sociedad como sujetos del derecho. Véase (Fernández Estrada et al., 2015; Díaz Aldret, 2017; Pérez Luño, 1991).
}

El proceso de planificación, por ejemplo, tiende a ser menos centralista y más participativo a partir de lo establecido en el artículo 20 del texto constitucional, el mismo dispone el derecho de los trabajadores a participar en los procesos de planificación de la economía. Sin embargo, siendo el trabajador el sujeto del derecho se limita el ejercicio del mismo al resto de los ciudadanos y otras organizaciones de la sociedad. Por demás, la participación en la planificación, al circunscribirse al ámbito laboral del trabajador, adquiere un carácter sectorial.

La nueva constitución reconoce en su artículo 191 b) como potestad de la Asamblea Municipal del Poder Popular aprobar y controlar el plan de la economía, el presupuesto y el plan de desarrollo integral del municipio. Este posicionamiento del constituyente apuesta por alcanzar mayores niveles de descentralización en el proceso de planificación de la economía; aun así, los mecanismos que viabilicen la articulación de las demandas ciudadanas dentro del plan de la economía y el presupuesto no quedan explícitas o al menos las bases constitucionales que permitan un adecuado desarrollo legislativo a tales fines. Estas inconsistencias emergen, en parte, al no reconocerse en el texto magno, como parte del amplio contenido de la participación ciudadana en los asuntos públicos, la participación ciudadana en la planificación y en la elaboración del presupuesto, cuestión que debió acontecer dentro del tan citado artículo 200. Por otra parte, aparece como causa primigenia, el tratamiento poco sistémico de las PP en el texto magno (no otorga autonomía al ente local para elaborar políticas públicas territoriales, no define las materias e instancias con facultades a tales efectos), todo lo cual limita su utilización como instrumento que permite al gobierno municipal acceder a las demandas ciudadanas y, construir una agenda de gobierno acorde con los intereses comunitarios y su posterior articulación con los planes locales y nacionales.

Con respecto al DL, la nueva constitución hace aportes significativos que contribuyen a fortalecer la capacidad municipal a tales efectos, vale citar el fortalecimiento de lo local como espacio participativo. En esa dirección, son legítimos los fundamentos esgrimidos supra, dígase autonomía, derecho de participación local, eliminación de las estructuras asamblearias provinciales y en su lugar la conformación de estructuras de gobierno.

Trascendente resulta la concepción del municipio como el ente local primario encargado de satisfacer las necesidades locales y no las necesidades mínimas, 
como lo establecía la carta magna de 1976. Por otra parte, se define el municipio desde una visión territorial y, además, se le considera una unidad política administrativa, con personalidad jurídica propia, reconociéndole los elementos culturales, sociales y económicos que lo caracterizan.

Finalmente, un elemento que fortalece los procesos de DL es el reconocimiento de la propiedad privada y la propiedad de instituciones y formas asociativas. El reconocimiento de estas formas de propiedad por la Ley de mayor rango, implica un desarrollo normativo posterior de éstas, en aras de definir el papel que deben ocupar en el plan de la economía del país, su rol frente a los problemas públicos. Por otra parte, entraña la redefinición de los fines y formas asociativas, así como los espacios y mecanismos interactivos entre las diferentes formas de propiedad reconocidas en el artículo 22 de la nueva carta magna.

\section{Conclusiones}

La doctrina cubana considera el DL como un proceso participativo que tiene como base primigenia la participación ciudadana en el diagnóstico de la propia política de DL y luego la participación en la definición ejecución y control de las PP que impulsan la estrategia trazada. Sin embargo, en la órbita normativa y específicamente desde la perspectiva de la Constitución de 1976 el tratamiento de la PP resulta limitado, al no contar los municipios con autonomía para la generación de PP territoriales. Estas inconsistencias en lo más alto del ordenamiento jurídico producen contradicciones e insuficiencias en el resto del sistema normativo en torno al propio DL y a la participación ciudadana en la gestión integral de las políticas públicas. La participación ciudadana en las PP adquiere su mayor dimensionamiento en el ordenamiento jurídico cubano en los Lineamientos de la Política Económica y Social del Partido y la Revolución y su posterior configuración en la Conceptualización del Modelo Económico y el Plan de Desarrollo Económico y Social hasta el 2030. La Constitución cubana de 2019, en materia de participación ciudadana y PP, es superior a la de 1976; sin embargo incurre en la misma limitación que su antecesora, es decir, no otorga a los municipios capacidad para formular PP territoriales, lo que a la postre puede constituirse en un límite al ejercicio del derecho de participación en las políticas públicas, al menos en su contenido esencial (elaboración, decisión, ejecución y evaluación de las PP). Por otra parte, en la constitución de 2019, no existe una de- finición concreta de las potestades y facultades que forman parte del contenido del derecho de participación ciudadana en la gestión pública, que garantice, ya desde el magno texto, su ejercicio efectivo.

\section{Referencias}

Asamblea Nacional del Poder Popular (2011). Lineamientos de la Política Económica y Social del Partido y la Revolución. Editora Política, La Habana.

Boisier, S. (2007). Territorio Estado y Sociedad en Chile. La Dialéctica de la Descentralización. Entre la Geografía y la Gobernabilidad.

Díaz Aldret, A. (2017). Participación ciudadana en la gestión y en las políticas públicas. Gestión y políticas públicas, 26(2):43-54.

Díaz Legón, O. (2015). Descentralización fiscal y desarrollo local en cuba. ideas preliminares (desde el derecho) para la articulación del proceso. En Pérez Hernández, L. y Díaz Legón, O., editores, ¿Que municipios queremos? Respuestas para Cuba en clave de desarrollo local y descentralización. Editorial UH, La Habana.

Fernández, O. (2012). Rasgos esenciales del modelo de funcionamiento económico en cuba. limitaciones y retos de las transformaciones en marcha. Economía y Desarrollo, 147(1):38-63.

Fernández Estrada, J. A., Tamayo Pineda, N., y Blanco Rojas, M. (2015). La competencia como presupuesto de la autonomía municipal. En Pérez Hernández, L. y Díaz Legón, O. J., editores, ¿Qué municipio queremos? Respuestas en clave de descentralización y desarrollo local. Editorial UH, La Habana.

Guanche, J. (2012). La participación ciudadana en el estado cubano. Temas, 70:69-79.

Guzón Camporredondo, A. (2004). Los municipios cubanos y sus potencialidades para el desarrollo local. Boletín Electrónico del CIPS, año I(3):616.

Guzón Camporredondo, A. (2015). A propósito del desarrollo local en cuba. En y O. J. Díaz Legón, L. P. H., editor, ¿̇ué municipio queremos? Respuestas en clave de descentralización y desarrollo local. Editorial UH, La Habana.

Hechavarria Prade, O. (2017). El presupuesto participativo un reto para el desarrollo local en cuba. 
Revista Estudio de Políticas Públicas, 3(1):157170.

Hernández Aguilar, O. (2014). La autonomía municipal en el constitucionalismo latinoamericano: realidad y perspectivas en el caso de cuba. Cuestiones Constitucionales, Revista Mexicana de Derecho Constitucional, 30.

León Segura, C. M. y Sorhegui, R. (2007). Repensar el desarrollo local en cuba. Economía y Desarrollo, 2:5-20.

Limia David, M. (2006). Notas introductorias. En Guzón, A., editor, Desarrollo Local en Cuba. Retos y Perspectivas. Editorial Academia, La Habana.

Limonta Montero, R. (2017). La participación ciudadana en la gestión de las finanzas públicas en el ordenamiento jurídico cubano.

Mulet Concepción, Y. (2015). Descentralización territorial: los gobiernos de artemisa y mayabeque. Revista Temas, 83:50-57.

Pérez Chaguaceda, A. (2008). Cuba, participación ciudadana y espacio asociativo: algunos apuntes. En Chaguaceda, A., editor, Participación y espacio asociativo. Ediciones Acuario, La Habana.

Pérez Hernández, L. y Prieto Valdés, M. (2004). Estado, gobierno y administración, diferenciación conceptual a propósito de la ley de los municipios. En Pérez Hernández, L. y Prieto Valdés, M., editores, Temas de Derecho Constitucional Cubano. Editorial Félix Varela, La Habana.

Pérez Luño, A. (1991). La generación de los derechos fundamentales. Revista del Centro de Estudios Constitucionales, 10:203-2172.

Plan Nacional de Desarrollo Económico y Social hasta 2030 (2016). Propuesta de Visión de la Nación, Ejes y Sectores Económicos Estratégicos. Editora Política, La Habana.

Rodríguez Cruz, Y. (2018). Información para el desarrollo sostenible en cuba: perspectiva gerencial desde la administración pública. En Congreso Internacional de Información. Cuba.

Santos Cid, C. M. y Peralta de Valle, E. (2003). Sistema presupuestario en Administración financiera del Estado cubano. Centro de Estudios Contables, Financieros y de Seguros, La Habana.
Torres Páez, C. y Gómez Ceballo, G. C. (2017). Las políticas públicas y su papel en la gestión del desarrollo local. 